\title{
Variations in gastric emptying of liquid elicited by acute blood volume changes in awake rats
}

\author{
F. de-A.A. Gondim, \\ G.R. de-O liveira, \\ J.R.V. Graça, \\ D.I.M. Cavalcante, \\ M.A.N. Souza, \\ A.A. Santos \\ and F.H. Rola
}

\author{
Departamento de Fisiologia e Farmacologia, Universidade Federal do Ceará, \\ Fortaleza, CE, Brasil
}

\author{
Correspondence \\ F.H. Rola \\ Laboratório Escola Prof. Luiz Capelo \\ Departamento de Fisiologia e \\ Farmacologia, UFC \\ Caixa Postal 3157 \\ Rua Coronel Nunes de Melo, 1127 \\ 60430-270 Fortaleza, CE \\ Brasil \\ Fax: 55 (085) 243-9333 \\ E-mail: meno@ufc.br
}

Research supported by CAPES, CN Pq, UNIMED and UFC. Part of this work was presented at the 8th European Symposium on Gastrointestinal Motility, Copenhagen, Denmark, 1996 and reported in abstract form (Neurogastroenterology and

Motility, 8: 166).

Received August 8, 1997

Accepted April 24, 1998

\section{Abstract}

We have observed that acute blood volume expansion increases the gastroduodenal resistance to the flow of liquid in anesthetized dogs, while retraction decreases it (Santos et al. (1991) Acta Physiologica Scandinavica, 143: 261-269). This study evaluates the effect of blood volume expansion and retraction on the gastric emptying of liquid in awake rats using a modification of the technique of Scarpignato (1980) (Archives Internationales de Pharmacodynamie et de Therapie, 246: 286-294). Male Wistar rats (180-200 g) were fasted for $16 \mathrm{~h}$ with water ad libitum and $1.5 \mathrm{ml}$ of the test meal $(0.5 \mathrm{mg} / \mathrm{ml}$ phenol red solution in $5 \%$ glucose) was delivered to the stomach immediately after random submission to one of the following protocols: 1) normovolemic control $(\mathrm{N}=22), 2)$ expansion $(\mathrm{N}=72)$ by intravenous infusion ( $1 \mathrm{ml} / \mathrm{min})$ of Ringer-bicarbonate solution, volumes of 1, 2, 3 or $5 \%$ body weight, or 3$)$ retraction $(\mathrm{N}=22)$ by controlled bleeding $(1.5 \mathrm{ml} / 100 \mathrm{~g})$. Gastric emptying of liquid was inhibited by $19-51.2 \%$ $(\mathrm{P}<0.05)$ after blood volume expansion (volumes of $1,2,3$ or $5 \%$ body weight). Blood volume expansion produced a sustained increase in central venous pressure while mean arterial pressure was transiently increased during expansion $(\mathrm{P}<0.05)$. Blood volume retraction increased gastric emptying by $28.5-49.9 \%(\mathrm{P}<0.05)$ and decreased central venous pressure and mean arterial pressure $(\mathrm{P}<0.05)$. Infusion of the shed blood $10 \mathrm{~min}$ after bleeding reversed the effect of retraction on gastric emptying. These findings suggest that gastric emptying of liquid is subject to modulation by the blood volume.

\section{Key words}

- Blood volume

- Hypervolemia

- Hemorrhage

- Central venous pressure

- Gastric emptying

- Gastrointestinal motility 


\section{Introduction}

Increasing evidence suggests that the gastrointestinal (GI) tract plays an active role in the acute management of blood volume (BV) imbalances, since acute BV changes modify the GI motor function (1-9) as well as its permeability to salt and water (10-15).

BV expansion decreases small bowel salt and water absorption and increases secretion (12-14) while BV retraction increases salt and water absorption and decreases secretion (11-15). These opposite responses appear to be regulatory in that they tend to correct a fluid imbalance $(10,11,13)$. In addition, intestinal electrolyte transport in humans is also modified by subtle BV changes triggered by postural changes, i.e., tilting maneuver or standing up (16).

Acute BV changes also modify the motor pattern of the GI tract. Firstly, we have observed that gastric and jejunal compliances are decreased by BV expansion while they are increased by BV retraction in anesthetized dogs $(2,3)$. In addition, utilizing a barostatically perfused system, we have observed that BV changes also modify the gastroduodenal resistance to saline flow in anesthetized dogs: BV expansion increases the resistance of the gastroduodenal segment to the flow of liquid while retraction decreases it $(4,5,8)$.

These observations suggested that gastric emptying (GE) of liquid could also be modulated by BV changes. Since our previous experiments were performed in anesthetized animals after rather invasive surgical procedures, the aim of the present study was to evaluate the effects of acute BV expansion and retraction on the GE of liquid in awake rats.

\section{Material and Methods}

\section{Animal preparation}

Male Wistar rats $(180-220 \mathrm{~g}, \mathrm{~N}=144)$, from our breeding station (Biotério da Universidade Federal do Ceará, Fortaleza, Brazil), were anesthetized with ether and polyethylene catheters (PE 50) filled with heparin $(500 \mathrm{U} / \mathrm{ml})$ were inserted into the left external jugular vein and right carotid artery. The distal end of each catheter was tunneled subcutaneously and its free end secured with a suture after a dorsal skin incision between the shoulders. Rats were allowed to recover for $16 \mathrm{~h}$ in individual raised mesh-bottom Bollman cages to prevent coprophagy, and were fasted with free access to water until $2 \mathrm{~h}$ before the experiment. All surgical procedures and animal treatments were conducted in accordance with the "Guide for the Care and Use of Laboratory Animals" (NIH), Bethesda, MD.

\section{Measurement of the gastric emptying of liquid}

The methodology used to measure the GE of liquid is essentially the same as described by Scarpignato (17). Firstly, $1.5 \mathrm{ml}$ of the test meal $(0.5 \mathrm{mg} / \mathrm{ml}$ phenol red solution in $5 \%$ glucose) was given orally into the stomach through a stainless steel tube that was removed immediately after delivering the meal. The animals were sacrificed by an $i v$ thiopental overdose at the assigned times $(0,5,10,20,30$ or 45 min after test meal administration). The stomachs were exposed by laparotomy, quickly clamped at the pylorus and cardia ends and then removed. Removed stomachs were placed in $100 \mathrm{ml}$ of $0.1 \mathrm{~N} \mathrm{NaOH}$, cut into small pieces and homogenized for $30 \mathrm{~s}$. The suspension was allowed to settle for $30 \mathrm{~min}$ at room temperature and $10 \mathrm{ml}$ of the supernatant centrifuged for $10 \mathrm{~min}(2800 \mathrm{rpm})$. Proteins in $5 \mathrm{ml}$ of this centrifuged supernatant were precipitated with $0.5 \mathrm{ml}$ of trichloroacetic acid $(20 \% \mathrm{w}: \mathrm{v})$ and centrifuged for $20 \mathrm{~min}$ (2800 rpm), and $3 \mathrm{ml}$ of this supernatant was added to $4 \mathrm{ml}$ of $0.5 \mathrm{~N} \mathrm{NaOH}$. The sample absorbance was read at a wave- 
length of $560 \mathrm{~nm}$ by spectrophotometry. Percent GE of liquid for each rat was calculated according to the following formula: $\mathrm{GE} \%=1$ - amount of phenol red recovered from test stomach/average amount of phenol red recovered from standard stomachs $\mathrm{x}$ 100.

Rats sacrificed immediately after test meal administration were used to establish standard stomach values $(100 \%$ phenol red in the stomach).

\section{Study design}

We randomly assigned groups of animals to one of the three following protocols: 1) Normovolemic control $(\mathrm{N}=22), 2)$ $\mathrm{BV}$ expansion $(\mathrm{N}=72)$, or 3$) \mathrm{BV}$ retraction $(\mathrm{N}=22)$. During the experiments, animals were maintained in standard cages in a quiet room. Immediately after submission to the selected protocol, the test meal was administered and the animals were sacrificed at different times $(0,5,10,20,30,45 \mathrm{~min})$ to measure GE rates. A group of 4 to 5 animals was utilized for each experimental time.

Normovolemic control animals $(\mathrm{N}=4$, $5,5,4$, and 4 , respectively, for GE measurement at 5, 10, 20, 30 and $45 \mathrm{~min}$ ) were submitted to standard procedures to simulate $\mathrm{BV}$ expansion/retraction manipulations but remained with their BV unchanged.

$\mathrm{BV}$ expansion was obtained by an iv infusion (Fars 600 pump, Lifemed) of Ringer bicarbonate solution $(140 \mathrm{mmol} / \mathrm{l}$ $\mathrm{Na}^{+}, 4 \mathrm{mmol} / 1 \mathrm{~K}^{+}, 124 \mathrm{mmol} / 1 \mathrm{Cl}^{-}, 20$ $\left.\mathrm{mmol} / \mathrm{HCO}_{3}^{-}\right), 1 \mathrm{ml} / \mathrm{min}$, in volumes of $1 \%(\mathrm{~N}=4$ for each experimental time at 10 , 20, 30 and $45 \mathrm{~min}), 2 \%(\mathrm{~N}=5,4,4$ and 4 , respectively, for each experimental time at $10,20,30$ and $45 \mathrm{~min}), 3 \%(\mathrm{~N}=4$ for each experimental time at 10,20,30 and $45 \mathrm{~min}$ ) or $5 \%(\mathrm{~N}=4,5,5,5$ and 4 , respectively, for each experimental time at $5,10,20,30$ and $45 \mathrm{~min}$ ) of body weight. The animals were gavage-fed immediately after expansion and sacrificed at different time intervals to evaluate the GE of liquid. To exclude the possibility that BV expansion could enhance gastric secretion and thus interfere with the measurement of the actual GE (17), another group of eight animals was pretreated with ranitidine $\left(\right.$ Antak $^{\circledR}, 10 \mathrm{mg} / \mathrm{kg}$, ip, Glaxo Wellcome, Rio de Janeiro, RJ, Brazil) $15 \mathrm{~min}$ before the experiments. Then, the animals were further submitted $(\mathrm{N}=4)$ or not (drug control, $\mathrm{N}=4$ ) to a BV expansion, up to a volume equivalent to $5 \%$ body weight immediately followed by gavage of the test meal.

$\mathrm{BV}$ retraction was obtained by controlled bleeding. A BV of $1.5 \mathrm{ml} / 100 \mathrm{~g}$ of body weight was slowly shed via the carotid artery $(1 \mathrm{ml} / \mathrm{min})$ and the animals received the test meal immediately after the end of this procedure. GE rates were evaluated using the same time intervals $(5,10$, 20, 30 and $45 \mathrm{~min}, \mathrm{~N}=4,5,5,4$ and 4 , respectively). In another group of 4 animals, we also evaluated whether hypovolemia correction could reverse the BV retraction effect upon the GE rates. Ten minutes after finishing the controlled hemorrhage, we slowly infused the previously shed blood via the carotid artery $(1 \mathrm{ml} /$ $\min )$. To avoid coagulation, the removed blood was maintained in a heparinized reservoir. At about 5 min after shed blood infusion, we administered the test meal and GE was evaluated 10 min later.

\section{Hemodynamic parameters}

In a separate group of animals, we evaluated the changes in mean arterial pressure (MAP) and central venous pressure (CVP) elicited by $\mathrm{BV}$ expansion (volume of $5 \%$ body weight) and retraction $(1.5 \mathrm{ml} / 100 \mathrm{~g}$ of body weight) in awake rats. MAP values were monitored every 2 min over a period of $60 \mathrm{~min}$, before and after the different protocols. For this purpose, the catheter placed into the carotid artery was connected 
Figure 1 - Rates of gastric emptying (GE) at 5, 10, 20, 30 and 45 min after test meal administration in Wistar rats. CONT $=$ Normovolemic control; EXP $(5 \%)=$ blood volume expansion by iv infusion of Ringer-bicarbonate solution, $1 \mathrm{ml} / \mathrm{min}$, in a volume of $5 \%$ body weight; RET = blood volume retraction by controlled hemorrhage of a volume of 1.5 $\mathrm{ml} / 100 \mathrm{~g}$. Data are reported as means $\pm \mathrm{SEM} . * \mathrm{P}<0.05 \mathrm{Stu}$ dent-Newman-Keuls test vs control values.

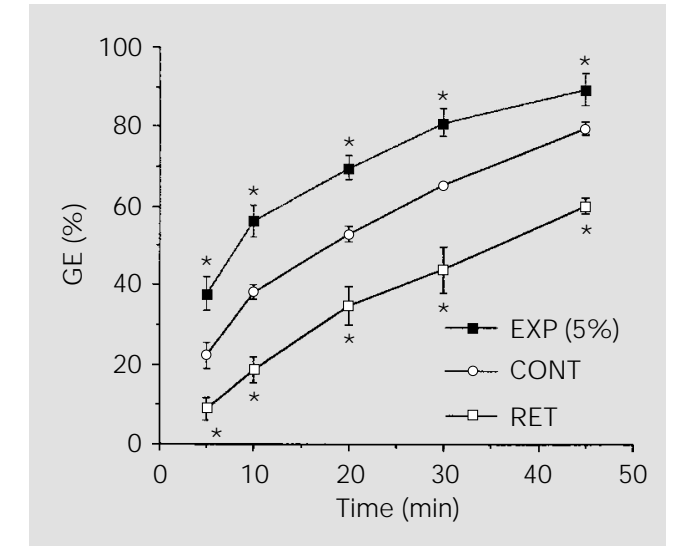

to a mercury manometer. CVP levels were also monitored every $2 \mathrm{~min}$ before and after the different treatments. The catheter inserted into the right jugular external vein was connected to a low pressure transducer (Statham-P23, Narco Byo-Systems Inc., Houston, TX) which was plugged to a Physiograph (Physiograph Desk Model DMD4B, Narco Byo-Systems Inc.). Intracardiac blood samples from controls and animals submitted to expansion (volume of 5\% body weight) or retraction $(1.5 \mathrm{ml} / 100 \mathrm{~g}$ of body weight) were collected for hematocrit determination after sacrifice.

\section{Statistical analysis}

The results are expressed as means \pm SEM. Descriptive statistics were applied to each group of experiments. One-way analysis of variance (ANOVA) and the StudentNewman-Keuls test were used to compare the various groups. Differences were considered significant at $\mathrm{P}<0.05$. Gastric residue curves from each experimental protocol (control, expansion and retraction) were constructed and the slopes tested with two computer programs (Sigma Stat for Windows Version 1.0, Copyright 1992-1994, Jandel Corporation, San Rafael, CA, USA). Linear logarithmic regression (where the log of gastric residues was plotted against time) was used according to Scarpignato (17) to determine the time taken to empty one-half of the meal (half-emptying time) \pm confidence intervals.

\section{Results}

\section{Effect of BV expansion and retraction on the GE of liquid}

Figure 1 compares the GE rates in normovolemic controls, BV-expanded $(5 \%$ body weight) and BV-retracted animals. The $\log$ of gastric residues decreased over time. Half-emptying time (t1/2) in normovolemic controls was $16.8 \pm 3.3 \mathrm{~min}(\mathrm{r}=0.94)$. BV expansion (5\% body weight) significantly decreased GE rates for at least $45 \mathrm{~min}$ and increased $\mathrm{t} 1 / 2$ to $31.6 \pm 6.5 \mathrm{~min}(\mathrm{r}=0.90)$. $\mathrm{BV}$ retraction increased $\mathrm{GE}$ rates for at least $45 \mathrm{~min}$ after retraction and decreased $\mathrm{t} 1 / 2$ to $7.6 \pm 3.7 \mathrm{~min}(\mathrm{r}=0.93)$. In a separate group, infusion of the shed volume $10 \mathrm{~min}$ after bleeding reversed the $\mathrm{BV}$ retraction effect on GE rates at $10 \mathrm{~min}(42.3 \pm 3.5$, NS vs control, $\mathrm{N}=4$ ).

Figure 2 shows GE rates according to the different levels of BV expansion (volumes of 1,2 and $3 \%$ body weight) compared with GE rates from normovolemic control animals. Half-emptying time was increased to $22.6 \pm 2.6(\mathrm{r}=0.94), 22.3 \pm 4.5(\mathrm{r}=0.93)$ and $30.1 \pm 3.6(\mathrm{r}=0.90) \mathrm{min}$, after BV expansions, volumes of 1,2 and $3 \%$ body weight. GE rates were significantly decreased for at least $20 \mathrm{~min}$ after 1 and $2 \%$ expansion but for at least $45 \mathrm{~min}$ after $3 \%$ expansion $(\mathrm{P}<0.05)$.

In the animals submitted to ranitidine pretreatment $(10 \mathrm{mg} / \mathrm{kg})$, GE percentages at 10 min were $43.4 \pm 4.2$ in ranitidine control animals and were significantly decreased to $24.7 \pm 2.5(\mathrm{P}<0.05)$ in ranitidine-treated animals submitted to BV expansion (volume of $5 \%$ body weight).

\section{Hemodynamic data}

MAP levels transiently increased during 
expansion from $112.2 \pm 3.2$ to $121.2 \pm 4.7$ $(\mathrm{P}<0.05)$. However, MAP was not significantly modified during the 45 -min time interval after expansion was completed (117.7 \pm 5.1 , NS $v s$ control levels). In contrast, BV retraction significantly decreased MAP values during retraction to $67.1 \pm 4.2(\mathrm{P}<0.05)$ and to $75.2 \pm 2.4$ during the 45 -min time interval after retraction $(\mathrm{P}<0.05)$. The MAP decrease observed after retraction was reversed by infusion of the shed blood ( $93.7 \pm$ $8.4 \mathrm{mmHg}$, NS vs control levels). CVP levels were increased from $3.1 \pm 1.6$ to $9.6 \pm 2.2$ $(\mathrm{P}<0.05)$ and to $7.9 \pm 3.4 \mathrm{cmH}_{2} \mathrm{O}(\mathrm{P}<0.05)$, respectively, during and after $\mathrm{BV}$ expansion. In contrast, during and after BV retraction, CVP levels were decreased to $-4.9 \pm 2.0$ $(\mathrm{P}<0.05)$ and $-3.8 \pm 1.6 \mathrm{cmH}_{2} \mathrm{O}(\mathrm{P}<0.05)$. Mean hematocrit values in control animals were $49.6 \pm 1.6 \%$ and were significantly decreased $(\mathrm{P}<0.05)$ after $\mathrm{BV}$ expansion to $34 \pm 1.1 \%$ while $B V$ retraction did not acutely modify mean hematocrit values: $48.3 \pm 1.4$ (NS vs control values).

\section{Discussion}

The present study shows that BV expansion and retraction consistently modify the GE of liquid in awake male Wistar rats, i.e., $\mathrm{BV}$ expansion delayed GE rates while BV retraction accelerated them (Figure 1). Halfemptying time was almost doubled after $\mathrm{BV}$ expansion, while it was reduced by about $50 \%$ after $\mathrm{BV}$ retraction.

The BV expansion effect varied according to the amount of volume infused, persisting for at least $45 \mathrm{~min}$ after expansions of 3 and $5 \%$ body weight, but only for $20 \mathrm{~min}$ after expansions of 1 and $2 \%$ body weight. It should be stressed that the effect of BV expansion on GE was observed even with the infusion of volumes equivalent to 1 and $2 \%$ body weight, a hemodynamic change which could be elicited by sudden postural changes (16) and thus it is not limited to the infusion of a large amount of fluid. BV

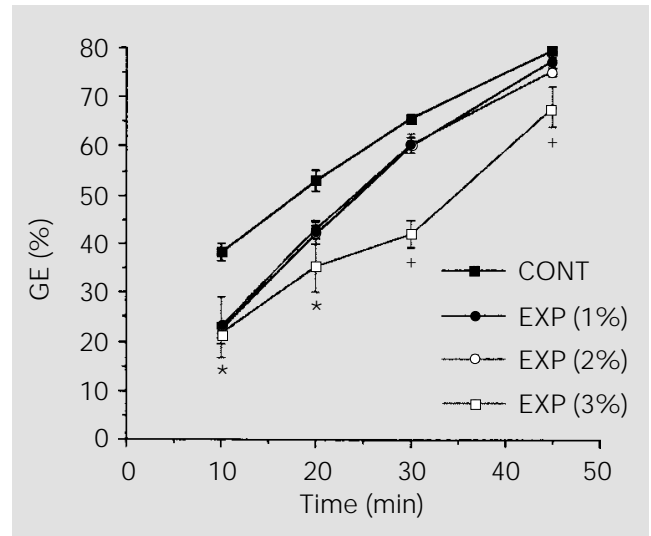

Figure 2 - Rates of gastric emptying (GE) in normovolemic control (CONT) or blood volume-expanded rats (EXP 1\%, 2\% and $3 \%$ ), by iv infusion of Ringerbicarbonate solution, $1 \mathrm{ml} / \mathrm{min}$, in volumes of 1,2 and $3 \%$ body weight, 10, 20, 30 and $45 \mathrm{~min}$ after test meal administration. Data are reported as means \pm SEM. $* \mathrm{P}<0.05$ for 1,2 and $3 \%$ EXP vs CONT; $+\mathrm{P}<0.05$ for $3 \%$ EXP vs CONT (Student-NewmanKeuls test). expansion after infusion equivalent to $3 \%$ body weight triggered a prolonged GE delay, which persisted for at least $45 \mathrm{~min}$, a pattern similar to that displayed by $5 \%$ body weight expansion. In turn, $\mathrm{t} 1 / 2$ was increased after all expansion levels (volumes of 1, 2, 3 and $5 \%$ body weight), with the maximum $t 1 / 2$ increase observed after $5 \%$ body weight expansion.

One explanation for the GE delay elicited by BV expansion would be the development of mucosal edema (18), since BV expansion modifies the Starling forces, increasing secretion and decreasing absorption (19). However, in an experimental model of portal hypertension the development of mucosal edema increased GE rates in rats (18). In addition, the interference of increased gastric acid secretion due to hypervolemia with the evaluation of the actual GE (17), a possible drawback, was minimized since the expansion effect persisted even after ranitidine pretreatment.

Another possibility is that the effect of $\mathrm{BV}$ expansion on GE is a consequence of changes on GI motility. This appears to be a more reasonable explanation since it is supported by our previous studies $(4,5,7,8)$, and reinforced by a recent observation that duodenal motility is increased by BV expansion in anesthetized dogs (7). We have also verified that the gastric fundus, as well as the duodenum may actively participate in the GE delay due to $\mathrm{BV}$ expansion $(8,9)$, but the possible 
pyloric participation cannot be completely excluded $(8,9)$.

The mechanisms of the effect of BV expansion on the GE of liquid have not been clearly established. However, our preliminary studies suggested the involvement of vagal pathways (1). In addition to a possible neural mechanism, BV expansion also leads to the release of atrial natriuretic peptide (ANP), other hormones and autacoids, which could interfere with both GI motility and intestinal absorption. ANP increases the magnitude of duodenal spontaneous contractions (20) and also reduces fluid/electrolyte absorption (21).

The accelerated GE we observed after $\mathrm{BV}$ retraction is consistent with the decreased GI contractile activity and decreased intestinal tone after BV retraction that has been previously described by others $(22,23)$. This effect has been suggested to be the result of adrenergic stimulation of tone and motility (5) which may counterbalance the effect of catecholamines on the GI sphincters (23). The increase in GE rates was also reversed by the infusion of the shed blood, in agreement with previous experiments (22), suggesting that the effect of bleeding on GE was $\mathrm{BV}$ dependent. In contrast to our findings, it has been observed that GE of liquid is delayed in rats submitted to chronic (72 h) water deprivation (24). These differences may be explained by the activation of different neurohumoral pathways, since our experiments were performed under acute conditions.

$\mathrm{BV}$ expansion transiently increased MAP levels while markedly increasing CVP levels and decreasing GE rates. Conversely, BV retraction decreased MAP and CVP levels, while it increased GE rates, an effect that was reversed by infusion of the shed blood. An inverse relationship between CVP and
GE values suggests the possibility of a blood volume-receptor regulation of the GE rates. In fact, we have previously observed that there is a consistent correlation between CVP values and the amplitude of duodenal contractions (7). These findings may be related to the previously described cardiac volumereceptor regulation of the jejunal fluid and electrolytes absorption/secretion ratio (10), which supports the view that the interplay between intestinal motility and permeability may be in some way important for blood volume hemostasis. In BV retraction an increase in GE could ease the contact of the liquid with the intestinal epithelium which is more absorptive after hemorrhage $(10,11,15)$. In fact, it has been shown that hemodynamic parameters can be stabilized by infusion of liquid into the stomach in hypovolemic shock (11). Conversely, the GE delay observed after BV expansion may be important to minimize the fluid volume being served to the small intestine (which increases its secretory capacity while decreasing absorption after expansion), until a new steady state is attained.

In conclusion, we have found that BV expansion and retraction respectively delayed and accelerated GE rates in awake rats. The BV retraction effect was reversed by shed blood infusion and the BV expansion effect varied according to the amount of liquid infused, indicating that $\mathrm{BV}$ modulates the GE of liquid.

\section{Acknowledgments}

We would like to thank Dr. Fernando Antônio A. Gondim and Dr. Rosalvo T.R. Fogaça for statistical support, Dr. Glauce B. Viana for kindly providing access to laboratory facilities, and Dr. David Criddle for revising the manuscript. 


\section{References}

1. Gondim F de AA, Oliveira GR, Graça J RV da, Cavalcante DIM, Gondim RBM, Santiago J r AT \& Rola FH (1996). Gastrointestinal motor reflexes elicited by acute blood volume expansion in awake rats. Neurogastroenterology and Motility, 8: 166 (Abstract).

2. Capelo LR, Cavalcante DM, Leitão IA, Cristino Filho G \& Silva EAT (1983). Modifications of gastric compliance in dogs related to changes of extracellular fluid volume. Brazilian J oumal of Medical and Biological Research, 16: 73-76.

3. Rola FH, Santos AA, Xavier-Neto J, Cristino Filho $\mathrm{G}$, Rocha $\mathrm{Cl}$, Santiago J $\mathrm{r}$ AT, Gondim FAA, Pereira J M \& Capelo LR (1989). Effects of acute volemic changes on the jejunal compliance in dogs. Brazilian J ournal of Medical and Biological Research, 22: 523-531.

4. Xavier-Neto J, dos Santos AA \& Rola FH (1990). Acute hypervolemia increases the gastroduodenal resistance to the flow of saline in rats. Gut, 31: 1006-1010.

5. Santos AA, Xavier-Neto J , Santiago J r AT, Souza MAN, Martins AS, Alzamora F \& Rola FH (1991). Acute volaemic changes modify the gastroduodenal resistance to the flow of saline in anaesthetized dogs. Acta Physiologica Scandinavica, 143: 261269.

6. Brummermann M \& Braun EJ (1995). Effect of salt and water balance on colonic motility of white leghorn roosters. American J ournal of Physiology, 268: R690R698.

7. Santos AA \& Oliveira SRB (1997). Acute volemic changes modify the duodenal motility in anesthetized dogs. In: Proceedings of the XXXIII International Congress of Physiological Sciences, St. Petersburg, Russia.

8. Graça J RV, Gondim F de AA, Oliveira GR, Rêgo MCV \& Rola FH (1997). Gastroduodenal resistance and neural mechanisms involved in saline flow decrease elicited by acute blood volume expansion in anesthetized rats. Brazilian J ournal of Medical and Biological Research, 30: 1257-1266.

9. Rêgo MCV, Graça J RV, Gondim F de AA, Gondim RB de M, Dantas RP \& Rola FH (1998). Role of proximal stomach and pylorus on gastric emptying and gastrointestinal transit delays elicited by acute blood volume expansion in awake rats. Brazilian J ournal of Medical and Biological Research, 31: 431-437.

10. Sjovall H, Redfors S, Biber B, Martner J \& Winso O (1984). Evidence for cardiac volume-receptor regulation of feline jejunal blood flow and fluid transport. American J ournal of Physiology, 246: G401-G410.

11. Miller WL \& Dale HE (1978). Restoration of hemorrhaged plasma volume by gastrointestinal fluid in the dog. American J ournal of Physiology, 234: H80-H87.

12. Duffy PA, Granger DN \& Taylor AE (1978). Intestinal secretion induced by volume expansion in the dog. Gastroenterology, 75: 413-418.

13. Mailman D \& J ordan K (1975). The effect of saline and hyperoncotic dextran infusion on canine ileal salt and water absorption and regional blood flow. Journal of Physiology, 252: 97-113.

14. Richet $G \&$ Hornych $A$ (1969). The effect of an expansion of extracellular fluid volume on the net sodium flux in the jejunum of rats. Nephron, 6: 365-378.

15. Redfors $S$, Hallback DA, Sjövall $H$, J odal $M \&$ Lundgren O (1984). Effect of hemorrhage on intramural blood distribution, villous tissue osmolality and fluid and electrolyte transport in cat small intestine. Acta Physiologica Scandinavica, 121: 211222.

16. Sjövall $H$, Abrahamsson $H$, Wstlander $G$, Gillberg R, Redfors S, J odal M \& Lundgren O (1986). Intestinal fluid and electrolyte transport in man during reduced circulat- ing blood volume. Gut, 27: 913-918.

17. Scarpignato $C$, Capovilla $T \&$ Bertacini $G$ (1980). Action of caerulein on gastric emptying of the conscious rat. Archives Internationales de Pharmacodynamie et de Therapie, 246: 286-294.

18. Reilly J r JA, Forst CF, Quigley EM \& Rikkers LF (1990). Chronic portal hypertension and gastric emptying in rats. Digestive Diseases and Sciences, 35: 781786.

19. Higgins J r J T \& Blair NP (1971). Intestinal transport of water and electrolytes during extracellular fluid volume expansion in dogs. J ournal of Clinical Investigation, 30: 2569-2579.

20. Bayens DA, Walters J M \& Vesely DL (1988). Atrial natriuretic factor increases the magnitude of duodenal spontaneous phasic contractions. Biochemical and Biophysical Research Communications, 155: 1437-1443.

21. Matsushita $\mathrm{K}$, Nishida $\mathrm{Y}$, Hosomi $\mathrm{H} \&$ Tanaka S (1991). Effects of atrial natriuretic peptide on water and $\mathrm{NaCl}$ absorption across the intestine. American J ournal of Physiology, 260: R6-R12.

22. Calabuig R, Seggerman RE, Weems WA, Weisbrodt NW \& Moody FG (1990). Gallbladder and gastrointestinal motility after hemorrhagic shock. Surgery, 107: 568573.

23. Furness J B \& Burstock G (1975). Role of circulating cathecolamines in the gastrointestinal tract. In: Blasko II, Sayers B \& Smith AD (Editors), Handbook of Physiology. Section 7, Endocrinology. Vol. VI. American Physiological Society, Washington.

24. Baracat ECE \& Collares SEF (1997). Gastric emptying of liquids in rats dehydrated by water deprivation. Brazilian J ournal of Medical and Biological Research, 30: 1363-1369. 